\title{
Genome-wide BAC-end sequencing of Cucumis melo using two BAC libraries
}

\author{
Víctor M González ${ }^{1 \dagger}$, Luis Rodríguez-Moreno ${ }^{2 \dagger}$, Emilio Centeno ${ }^{1}$, Andrej Benjak ${ }^{3}$, Jordi Garcia-Mas ${ }^{3}$, \\ Pere Puigdomènech', Miguel A Aranda ${ }^{2 *}$
}

\begin{abstract}
Background: Although melon (Cucumis melo L.) is an economically important fruit crop, no genome-wide sequence information is openly available at the current time. We therefore sequenced BAC-ends representing a total of 33,024 clones, half of them from a previously described melon BAC library generated with restriction endonucleases and the remainder from a new random-shear BAC library.

Results: We generated a total of 47,140 high-quality BAC-end sequences (BES), 91.7\% of which were paired-BES. Both libraries were assembled independently and then cross-assembled to obtain a final set of 33,372 nonredundant, high-quality sequences. These were grouped into 6,411 contigs (4.5 Mb) and 26,961 non-assembled BES $(14.4 \mathrm{Mb})$, representing $\sim 4.2 \%$ of the melon genome. The sequences were used to screen genomic databases, identifying 7,198 simple sequence repeats (corresponding to one microsatellite every $2.6 \mathrm{~kb}$ ) and 2,484 additional repeats of which $95.9 \%$ represented transposable elements. The sequences were also used to screen expressed sequence tag (EST) databases, revealing 11,372 BES that were homologous to ESTs. This suggests that $~ 30 \%$ of the melon genome consists of coding DNA. We observed regions of microsynteny between melon paired-BES and six other dicotyledonous plant genomes.

Conclusion: The analysis of nearly 50,000 BES from two complementary genomic libraries covered $\sim 4.2 \%$ of the melon genome, providing insight into properties such as microsatellite and transposable element distribution, and the percentage of coding DNA. The observed synteny between melon paired-BES and six other plant genomes showed that useful comparative genomic data can be derived through large scale BAC-end sequencing by anchoring a small proportion of the melon genome to other sequenced genomes.
\end{abstract}

\section{Background}

Melon (Cucumis melo L.) is an important horticultural crop grown in temperate, subtropical and tropical regions worldwide. More than 25 million tonnes of fruit were produced in 2007, 64.5\% in Asia, 14.6\% in Europe, $13.1 \%$ in America and 7.8\% in Africa [1]. Melon belongs to the Cucurbitaceae family, which comprises 90 genera and $\sim 750$ species, including other fruit crops such as watermelon (Citrullus lanatus (Thunb.) Matsum \& Nakai), cucumber (Cucumis sativus L.), squash and pumpkin (Cucurbita spp.). Genetically, melon is a

\footnotetext{
* Correspondence: m.aranda@cebas.csic.es

+ Contributed equally

${ }^{2}$ Departamento de Biología del Estrés y Patología Vegetal, Centro de Edafología y Biología Aplicada del Segura (CEBAS) - CSIC, Apdo. correos 164, 30100 Espinardo (Murcia), Spain

Full list of author information is available at the end of the article
}

diploid species $(2 \times=2 \mathrm{n}=24)$ with an estimated genome size of $454 \mathrm{Mb}$ [2]. Transgenic melons, first produced in 1990, can now be generated in a range of recalcitrant cultivars $[3,4]$. Melon fruits are morphologically and biochemically diverse, which makes them particularly suitable for research into the flavor and texture changes that occur during ripening [5].

Despite its economic importance, there are few genomic resources for melon. As of January 2010, 126,940 highquality expressed sequence tags (ESTs) and 23,762 unigenes were available in public databases [6,7], which is low when compared to the 298,123 ESTs available for tomato (Solanum lycopersicum L.) and the 1,249,110 ESTs available for rice (Oryza sativa L.) [8]. More recent efforts to increase the availability of genetic and genomic resources for melon [9] have included the construction of bacterial artificial chromosome (BAC) libraries [10,11], the

\section{Biomed Central}


development of oligo-based microarrays $[12,13]$, the production of TILLING and EcoTILLING platforms [14,15] and the development of a collection of near isogenic lines (NILs) [16]. However, the integration of genetic and physical maps is a necessary first step towards sequencing the melon genome, identifying relevant genes using these to discover how economically important aspects of fruit development are controlled $[17,18]$.

Over the last 15 years, several melon genetic maps have been constructed primarily using randomly amplified polymorphic DNAs (RAPDs), restriction fragment length polymorphisms (RFLPs), amplified fragment length polymorphisms (AFLPs) and simple sequence repeats (SSRs) [19-24]. These maps have helped to pinpoint the loci of some important agronomic traits [25-27], but they are sparsely populated and the different markers make them difficult to compare. To address this issue, a genetic map has recently been constructed by merging several of those previous genetic maps [6]. In addition, a melon physical map representing $0.9 \times$ melon genomic equivalents has recently been constructed using both a BAC library and a genetic map previously developed in our laboratory [28]. The physical and genetic maps have been integrated by anchoring 175 genetic markers to the physical map, allowing contigs representing $12 \%$ of the melon genome to be anchored to known genetic loci.

It is important to obtain an accurate, representative sample of the genome ahead of full genome sequencing and annotation, and the end-sequencing of large numbers of BAC clones is an efficient strategy to achieve this goal. BAC-end sequences (BES) generate accurate but inexpensive genome samples that give a first impression of properties such as GC content, the distribution of microsatellites and transposable elements, and the amount of coding DNA [29-31]. However, most BAC libraries are constructed by digesting DNA with one or more restriction endonucleases, which introduces a partial bias in coverage because the target sites are distributed in a non-random manner [32]. We therefore sequenced BAC-ends representing 33,024 clones, half from a previously described BAC library generated using restriction endonucleases, but the remainder from a freshly-prepared random shear BAC library to eliminate the possibility of bias. We obtained 47,140 high-quality BES, which were analyzed for GC content, microsatellites, repeat elements and coding regions. A total of 43,224 paired BES were mapped independently onto six sequenced genomes from other dicotyledonous plant species to identify regions of microsynteny.

\section{Results and discussion BAC libraries}

Two BAC libraries from the double-haploid melon line PIT92 were used for BAC-end sequencing (Table 1).
Table 1 Genomic C. melo BAC libraries

\begin{tabular}{lcc}
\hline & BCM & RCM \\
\hline Vector & pECBAC1 & pSMART \\
Digestion method & BamHI & Random shear \\
Average insert size & $139 \mathrm{~kb}$ & $120 \mathrm{~kb}$ \\
No. of clones & 23,040 & 30,720 \\
Estimated No. of true clones $^{\mathbf{1}}$ & 18,432 & 23,655 \\
Genomic coverage $^{\mathbf{2}}$ & $\times 5.7$ & $\times 6.4$
\end{tabular}

${ }^{1}$ Non-empty BAC clones containing melon genomic DNA

${ }^{2}$ Based on an estimated haploid genome size of $454 \mathrm{Mb}$ [2]

A BamHI BAC library (BCM) had previously been constructed in our laboratory with an average insert size of $139 \mathrm{~kb}$, representing 5.7 genome equivalents of the melon haploid genome (based on an estimated haploid genome size of $454 \mathrm{Mb}$ [2]) [11]. In order to increase the genome coverage and reduce the bias associated with BAC libraries constructed using non-random DNA fragments, a second BAC library (RCM) was prepared using randomly-sheared melon genomic DNA. With 30,720 BAC clones and an average insert size of $120 \mathrm{~kb}$, this library represents 6.4 genomic equivalents. When combined, the two libraries represent $\sim 12$ genomic equivalents.

Fingerprinting of clones from the BCM library allowed the construction of a melon physical map [28]. The analysis of the structure of the BAC contigs revealed a high proportion of 'stacked' contigs, that is, contigs containing regions of depth that exceeded by far the estimated coverage of the library used $(5.7 \times)$; in fact, most of the contigs contained BACs sharing one border, a feature most probably explained by the unequal use of BamHI restriction sites during library construction. These data strongly suggest that the BCM library could be heavily affected by the non-randomness currently associated to all libraries constructed by one-enzyme restriction of genomic DNA. On the contrary, being a random shear library, RCM should represent more randomly the melon genome, although some bias produced by unequal DNA fragmentation cannot be ruled out.

\section{BAC end sequencing}

We sequenced the ends of 16,512 BCM BACs and 16,512 RCM BACs, generating 23,878 and 23,262 highquality BES, respectively (Table 2). Together, this amounted to 47,140 high-quality BES, of which $91.7 \%$ were paired-BES. The average read length was $543 \mathrm{bp}$, representing $25.6 \mathrm{Mb}$ of genomic DNA in total or $5.7 \%$ of the genome (using the $454 \mathrm{Mb}$ estimate [2]). The BES have been deposited in the GenBank databases under the accession numbers HN291986-HN339125.

As any analysis based on a highly redundant set of BES would produce unaccurate genomic information, 
Table 2 Sequence statistics of the $C$. melo BES

\begin{tabular}{|c|c|c|c|}
\hline & BCM & RCM & Total \\
\hline \multicolumn{4}{|l|}{ Total BES } \\
\hline Total no. of high-quality BES & 23,878 & 23,262 & 47,140 \\
\hline paired-BES & 21,742 & 21,482 & 43,224 \\
\hline non-paired BES & 2,136 & 1,780 & 3,916 \\
\hline Minimum/maximum length (bp) & $50-879$ & $50-874$ & $50-879$ \\
\hline Average length (bp) & 552 & 534 & 543 \\
\hline \multirow[t]{2}{*}{ Total length (Mb) } & 13.2 & 12.4 & 25.6 \\
\hline & $\mathrm{BCM}$ & RCM & BCM-RCM \\
\hline \multicolumn{4}{|l|}{ Non-redundant sequences ${ }^{1}$} \\
\hline Total no. Of: & 15,408 & 19,106 & 33,372 \\
\hline contigs & 4,661 & 1,488 & 6,411 \\
\hline singletons & 10,747 & 17,618 & 26,961 \\
\hline Total length $(\mathrm{Mb})$ & 8.9 & 10.5 & 18.9 \\
\hline Minimum/maximum length (bp) & & & $50 / 3,473$ \\
\hline Average length (bp) & & & 658 \\
\hline
\end{tabular}

the $\mathrm{BCM}$ and RCM BES were assembled independently to reduce sequence redundancy. In order to avoid as much as possible the incorrect assembly of highly repetitive genomic regions, the assembly was performed using rather strict constraints (see Methods section). The BCM assembly produced 4,661 contigs with a total length of $3.1 \mathrm{Mb}$, as well as 10,747 singletons $(5.9 \mathrm{Mb})$, whereas the RCM assembly produced 1,488 contigs $(1.2 \mathrm{Mb})$ as well as 17,618 singletons $(9.2 \mathrm{Mb})$. Although the numbers of high-quality BES, paired-BES and the average read length were similar for both libraries, only $45 \%$ of the BCM BES remained as singletons after assembly, compared to $76 \%$ of the RCM BES. Furthermore, the average length of contigs comprising two BES was $631 \mathrm{bp}$ for the BCM assembly and $715 \mathrm{bp}$ for the $\mathrm{RCM}$ assembly. These data support the conclusion that the RCM BES are more uniformly distributed across the melon genome than those from the BCM library, as anticipated from the construction methods. The nonrandom distribution of restriction endonuclease target sites and cytosine methylation targets has promoted research into a number of alternative library construction methods, including the random shearing approach used here and the use of methylation-sensitive partial restriction digests [32-34].

A final combined set of non-redundant, high-quality BES (named BCM-RCM) was produced after the crossassembly of the BCM and RCM contigs and singletons. This contained 33,372 sequences of average length 568 bp and total length 18.9 $\mathrm{Mb}$, grouped in 6,411 contigs $(4.5 \mathrm{Mb})$ and 26,961 non-assembled BES (14.4 Mb). Only 997 (15\%) contigs were longer than the maximum BES length (879 bp). The average GC content was
$35.2 \%$, similar to previous values from sequenced melon BAC clones [11,35].

Significantly, the total length of the BCM-RCM assembly was just $430 \mathrm{~kb}$ shorter, and contained only 1,142 less sequences, than the global length of the $\mathrm{BCM}$ and RCM assemblies on the whole (Table 2). Thus, almost no redundancy seems to exist between BES from the $\mathrm{BCM}$ library and those from the RCM library, strongly suggesting that incorrect assembly of BES from duplicate or repetitive genomic regions should not represent a significant reason behind the high redundancy detected when assembling BCM and RCM BES; otherwise, similar levels of redundancy would had been detected when cross-assembling the BCM and RCM contigs and singletons, contrary to our results.

\section{Simple sequence repeats}

The BCM-RCM sequences were screened for SSRs, resulting in the identification of 7,198 microsatellites at least $12 \mathrm{nt}$ in length (1-3 nt repeats) or containing at least four tandem repeat units (4-6 nt repeats). SSRs accounted for $130,222 \mathrm{bp}(0.7 \%)$ of the total BCM-RCM sequence, which is equivalent to one microsatellite every $2.6 \mathrm{~kb}$ (Table 3). Mononucleotide tandem repeats were the most abundant, accounting for $39.7 \%$ of all microsatellites, followed by trinucleotides (27.4\%) and dinucleotides $(24.2 \%)$. The poly $(\mathrm{A}) / \operatorname{poly}(\mathrm{T})$ microsatellite was the most common mononucleotide repeat (94.6\%) and the poly(AT) microsatellite was the most common dinucleotide repeat $(67.8 \%)$. These data confirm previous results from the analysis of two melon BAC clones $[11,36]$ although dinucleotide repeats appear to be less abundant in melon than in many other plants, e.g. apple, tomato, potato, clementine, papaya and banana [29,31,37-39].

A total of 1,439 (20\%) microsatellites were found to be $>20$ nucleotides in length (class I microsatellites) making them good candidates for hypervariable, polymorphic markers. The longest microsatellites repeat units of 1-4 nucleotides were a 57-bp poly(T) sequence, a 102-bp poly(AT) repeat, a 465-bp poly(AAT) repeat and a 172-bp poly(ACAT) repeat. The most abundant SSRs for each repeat unit category were generally ATrich, although exceptionally the most abundant pentanucleotide repeat was AGCCG/CGGCT (representing 40\% of all pentanucleotide tandem repeats).

The above analysis was also carried out individually on the BCM and RCM assemblies. When values in Table 3 were normalized relative to the total sequence length of each assembly, RCM was found to contain 1.2 times more SSRs than BCM, with some specific cases (namely C/G, ACAT/ATGT, AGCCG/CGGCT and AATTT/ AAATT repeats) showing a marked increase in the microsatellite content of RCM relative to $\mathrm{BCM}$ (between 
Table 3 Distribution of SSRs in C. melo non-redundant sequences

\begin{tabular}{cccc}
\hline Type & \multicolumn{3}{c}{ Number } \\
\hline & BCM & RCM & BCM - RCM \\
\hline
\end{tabular}

Monomer

\begin{tabular}{|c|c|c|c|c|}
\hline & $A / T$ & 1,192 & 1,546 & 2,700 \\
\hline & $C / G$ & 47 & 110 & 155 \\
\hline \multicolumn{5}{|l|}{ Dimer } \\
\hline & AT & 482 & 710 & 1,184 \\
\hline & $\mathrm{AG} / \mathrm{CT}$ & 190 & 250 & 429 \\
\hline & $\mathrm{AC} / \mathrm{GT}$ & 59 & 69 & 128 \\
\hline & $C G$ & 4 & 0 & 4 \\
\hline \multicolumn{5}{|l|}{ Trimer } \\
\hline & AAT/ATT & 392 & 674 & 1050 \\
\hline & AAG/CTT & 217 & 332 & 546 \\
\hline & ATC/GAT & 47 & 39 & 85 \\
\hline & AAC/GTT & 31 & 38 & 68 \\
\hline & AGG/CCT & 36 & 37 & 72 \\
\hline & Other & 69 & 90 & 150 \\
\hline \multicolumn{5}{|l|}{ Tetramer } \\
\hline & AAAT/ATTा & 65 & 95 & 159 \\
\hline & AAAG/CTIT & 35 & 42 & 75 \\
\hline & AATT & 20 & 21 & 39 \\
\hline & ACAT/ATGT & 5 & 21 & 26 \\
\hline & AAAC/GTTा & 9 & 9 & 17 \\
\hline & Other & 18 & 19 & 37 \\
\hline \multicolumn{5}{|l|}{ Pentamer } \\
\hline & AGCCG/CGGCT & 22 & 62 & 84 \\
\hline & AAAAG/CTITT & 21 & 26 & 47 \\
\hline & AAAAT/ATTाT & 13 & 10 & 22 \\
\hline & AAAAC/GTITT & 6 & 6 & 12 \\
\hline & AATTT/AAATT & 3 & 7 & 9 \\
\hline & Other & 22 & 16 & 36 \\
\hline \multicolumn{5}{|l|}{ Hexamer } \\
\hline & AAAAAG/CTITIT & 9 & 6 & 15 \\
\hline & AAAAAT/ATTTT & 3 & 3 & 6 \\
\hline & AAAGAG/CTCTIT & 2 & 1 & 3 \\
\hline & GAATTT/AAATTC & 0 & 2 & 2 \\
\hline & Other & 15 & 23 & 38 \\
\hline & & $\begin{array}{l}\text { Total: } \\
\mathbf{3 , 0 3 4}\end{array}$ & $\begin{array}{c}\text { Total: } \\
\mathbf{4 , 2 6 4}\end{array}$ & Total: $\mathbf{7 , 1 9 8}$ \\
\hline & & $\begin{array}{c}\text { Total } \\
\text { length: } \\
54,754 \text { bp }\end{array}$ & $\begin{array}{c}\text { Total } \\
\text { length: } \\
77,267 \text { bp }\end{array}$ & $\begin{array}{c}\text { Total } \\
\text { length: } \\
130,222 \text { bp }\end{array}$ \\
\hline
\end{tabular}

Length

distribution x2 for AATTT/AAATT and x3.6 for ACAT/ATGT). Significantly, the number of SSRs longer than $100 \mathrm{nt}$ was found to be four times higher in RCM than in BCM while the number of SSRs shorter than 100 nt was only 1.1 times greater in RCM than in BCM. We therefore conclude that the RCM library represents genomic regions with a higher content and different distribution of microsatellites than those covered by the BCM library.

We validated these results by searching for microsatellites in the melon unigene collection (v3) at ICUGI [6] using identical search parameters. A total of 7,038 SSRs was found among 23,762 unigenes spanning $18.5 \mathrm{Mb}$ of the melon transcriptome. These microsatellites represent $125,363 \mathrm{bp}$, or $0.7 \%$ of the total combined unigene sequence, a density of one SSR every $2.6 \mathrm{~kb}$. Although these figures are equivalent to those obtained using the BCM-RCM assembly, the relative abundance of 1-6 nucleotide repeat microsatellites was quite different, with trinucleotide repeats the most abundant class (47\%), followed by mononucleotide $(24.8 \%)$ and dinucleotide $(20.7 \%)$ repeats. SSR frequency and type are known to differ between coding DNA, intron DNA and intergenic DNA [40], and it has previously been shown that trinucleotide repeats are the most abundant SSRs in plant coding regions [41].

\section{Repetitive elements}

The BCM-RCM assembly was compared with the plant repeat databases at http://plantrepeats.plantbiology.msu. edu/ and also screened using RepeatMasker software to locate transposable elements, rRNAs and telomereand centromere-related sequences. A total of 2,484 sequences showed homology with plant repeat elements (representing 6\% of the assembly) of which $95.9 \%$ were transposable elements (TEs) (Table 4). Class I transposons (retrotransposons) were the most abundant, accounting for $85.4 \%$ of TEs. Sequences homologous to retrotransposons were classified as LTR-containing Ty1Copia (61.6\%) and Ty3-Gypsy (34.9\%), LINES (1.5\%) and other unclassified elements (2\%). The next most abundant repeats were class II transposons, $51 \%$ of which were classified as En-Spm elements. These figures are similar to those obtained from cucumber, where retrotransposons accounted for $81 \%$ of all TEs, the Ty1/ Ty3 ratio is 1.4, and En-Spm elements accounted for $54 \%$ of all classified DNA transposons [42]. Other plant repeat elements included twelve putative rolling-circle transposons, $105 \mathrm{rDNA}$ sequences and three putative telomere-related sequences.

The BCM and RCM assemblies were searched independently for plant repeat sequences and the class 
Table 4 Plant repeat element content of C. melo nonredundant sequences

\begin{tabular}{|c|c|c|c|c|}
\hline \multirow[b]{2}{*}{ Class } & \multirow[b]{2}{*}{ Element } & \multicolumn{3}{|c|}{$\mathrm{BCM}-\mathrm{RCM}$} \\
\hline & & No. & Total & $\%$ \\
\hline Retroelements & & & 2,030 & 3.8 \\
\hline \multirow[t]{2}{*}{ LINES } & & 30 & & \\
\hline & L1 & 30 & & \\
\hline \multirow[t]{4}{*}{ LTR } & & 2,000 & & \\
\hline & Ty1/Copia & 1,250 & & \\
\hline & Ty3/Gypsy & 709 & & \\
\hline & Unclassified & 41 & & \\
\hline \multirow[t]{6}{*}{ DNA transposons } & & & 335 & 1.9 \\
\hline & hobo-Activator & 35 & & \\
\hline & En-Spm & 171 & & \\
\hline & MuDR & 102 & & \\
\hline & Harbinger & 5 & & \\
\hline & Unclassified & 22 & & \\
\hline \multirow[t]{2}{*}{ Rolling circles } & & & 12 & 0.02 \\
\hline & Helitron & 12 & & \\
\hline $\begin{array}{l}\text { Telomere-related } \\
\text { Sequences }\end{array}$ & & & 3 & \\
\hline \multirow[t]{4}{*}{ rRNA genes } & & & 105 & 0.3 \\
\hline & Small subunit & 36 & & \\
\hline & Large subunit & 62 & & \\
\hline & $45 S$ and Internal spacer region & 7 & & \\
\hline $\begin{array}{l}\text { Total no. of } \\
\text { repeat elements }\end{array}$ & & & 2,484 & 6.0 \\
\hline
\end{tabular}

I/class II ratio was found to be the same from both sources. However, some differences were detected regarding the relative abundance of specific transposon subfamilies. While En/Spm elements were the most abundant class II transposons in the RCM assembly, accounting for $64 \%$ of all DNA transposons and followed by MuDR elements (18\%), En/Spm transposons accounted for only $37 \%$ of TEs in the BCM assembly, with MuDRs representing 43\% of DNA transposons. Also, the Ty1/Ty3 ratios were 2 and 1.5 in the BCM and RCM assemblies, respectively. Significantly, whereas the RCM assembly contained 84 putative rDNA sequences, only 29 were found in the BCM assembly. The genes for the $18 S, 5.8 S$ and $25 S$ ribosomal RNAs are present in tandem arrays containing up to 20,000 repeats in a chromosome structure known as the nucleolar organizer region [42]. Genomic regions containing highly repetitive sequences arranged in tandem repeats are often underrepresented in genomic libraries constructed using one restriction endonuclease. Therefore, our data suggest that the melon RCM library represents genomic regions not covered or poorly represented by the BCM library.

\section{Coding regions}

BCM-RCM non-redundant and masked sequences were tested against the 23,762 sequences from the melon unigene database v3 [6] using the BLASTN algorithm (Table 5). Because this approach compares short fragments of genomic DNA against ESTs, the use of stringent match conditions would fail to detect most BES containing intron-exon boundaries, whereas less stringent conditions would increase the number of false positives. As a compromise, a double cut-off approach was used with a low-stringency $\mathrm{E}$ value of $10^{-20}$ and a highstringency value of $10^{-50}$. The low-stringency search identified 7,929 matching sequences, with 4,661 showing $>95 \%$ identity to melon unigenes. The remaining unmatched sequences were then used to search other cucurbit unigene databases $(81,401$ unigenes from the cucumber EST collection v2, and 4,719 unigenes from the watermelon EST collection v1) [6]. A total of 3,064 additional sequences showed homology to those cucurbit unigene sets. Finally, sequences that failed to match any cucurbit EST databases were used to search all noncucurbit plant EST assembly databases at http://www. plantgdb.org and 379 additional hits were found. In all, $11,372(34.1 \%)$ of the analyzed sequences were shown to contain putative regions of coding DNA. The highstringency search identified 6,630 hits or $19.9 \%$ of all tested sequences. These results suggest that between $20 \%$ and $35 \%$ of the melon genome consists of coding DNA.

Melon unigene hits accounted for $72.1 \%$ of cucurbit hits, or $69.7 \%$ of all hits, in the low-stringency search, and for and $77.4 \%$ of cucurbit hits, or $76.5 \%$ of all hits, in the high-stringency search. This suggests that the current melon unigene database at ICUGI lacks 22-30\% of all melon transcripts. Because the melon unigene database contains 23,762 unigenes, we can tentatively estimate that the total size of the melon transcriptome is $27,000-34,000$ sequences.

\section{Comparative mapping of melon BES onto other plant genomes}

The analysis of two regions of the melon genome $92 \mathrm{~kb}$ and $215 \mathrm{~kb}$ in length has previously revealed significant degrees of microsynteny between melon and Arabidopsis thaliana, poplar (Populus trichocarpa) and Medicago truncatula $[11,35]$. Syntenic relationships facilitate the investigation of genome evolution and dynamics, comparative genomics and phylogeny $[43,44]$, as well as allowing agronomically important genes to be identified and cloned [45]. For example, the melon nsv locus, which confers resistance to Melon necrotic spot virus, was cloned by exploiting synteny [46].

In order to identify regions of synteny between the melon genome and other sequenced plant genomes, all 47,140 high quality BES were masked for repeats and 
Table 5 BLASTN analysis against plant EST databases

\begin{tabular}{|c|c|c|c|c|}
\hline \multirow[t]{2}{*}{ Masked and non-redundant $C$. melo sequences vs.: } & \multicolumn{2}{|c|}{ E-value $1 \times 10^{-20}$} & \multicolumn{2}{|c|}{ E-value $1 \times 10^{-50}$} \\
\hline & No. of hits & $\%^{1}$ & No. of hits & $\%^{1}$ \\
\hline Melon unigenes ${ }^{2}$ & 7,929 & 23.7 & 5,072 & 15.2 \\
\hline Cucumber/watermelon unigenes $^{3}$ & 3,064 & 9.2 & 1,478 & 4.4 \\
\hline Non-cucurbit plant ESTs ${ }^{4}$ & 379 & 1.1 & 80 & 0.2 \\
\hline Total: & 11,372 & 34.1 & 6,630 & 19.9 \\
\hline
\end{tabular}

${ }^{1}$ Relative to the number of non-redundant $\mathrm{C}$. melo BCM-RCM sequences

${ }^{2}$ ICUGI melon_unigen_v3 [6]

${ }^{3}$ ICUGI cucumber_unigen_v2 and watermelon_unigen_v1 [6]

${ }^{4}$ All non-cucurbit plant EST assembly databases from http://www.plantgdb.org

used to search the genome sequences available in the Phytozome v5.0 database http://www.phytozome.net. Six dicotyledonous species were chosen for the analysis: A. thaliana, cucumber, soybean (Glycine max), M. truncatula, poplar and grapevine (Vitis vinifera). Only scaffolds $>500 \mathrm{~kb}$ in length were used for comparative mapping in cucumber because the contiguity of the cucumber genome sequence is currently low. The cucumber scaffolds represent $149 \mathrm{Mb}$ or $73.4 \%$ of the sequence assembly deposited in the Phytozome database and $61 \%$ of the cucumber genome [47]. As shown in Table 6, 6-10\% of melon BES matched non-curcubit genomes $(9-14 \%$ were paired BES), and $65 \%$ of melon BES matched the cucumber genome (67\% were paired $\mathrm{BES})$. A thaliana showed the lowest number of hits whereas grapevine, poplar and soybean showed similar levels. Because only $\sim 70 \%$ of the complete cucumber genome was used, we estimate that more than $90 \%$ of all melon BES would show significant homology to the whole cucumber genome sequence if available.

Synteny between the melon genome and other plants was characterized by searching the BCM-RCM sequence for paired BES that 1) mapped to the same chromosome, 2) within a 50-500 kb region and 3) were oriented correctly with respect to each other. According to these criteria, $0.05-0.35 \%$ of all paired BES were deemed potentially collinear with the other plant genomes (except cucumber, see below). Again, A. thaliana showed the lowest number of hits (11), followed by M. truncatula (24), grapevine (56), soybean (57) and poplar (76). The higher degree of synteny between melon and poplar compared to melon and M. truncatula, despite the Cucurbitales being considered phylogenetically closer to Fabales than to Malphigiales, is consistent with previous results from the analysis of two independent melon regions [35]. In cucumber, 4,138 paired BES (19\% of all available paired BES) fulfilled the three syntenic conditions listed above. However, the available cucumber genomic sequence is not yet assembled into chromosomes, and the scaffolds $>500$ $\mathrm{kb}$ are represented by only $\sim 150$ sequences. Therefore, a significant number of true collinear paired BES could not be detected due to paired BES mapping into different but adjacent cucumber scaffolds, and so the number of paired BES potentially collinear with the cucumber genome is probably much higher than the above value.

When the requirement for correct orientation was omitted to consider collinear regions that may have suffered localized inversions, there was an increase of $20-56 \%$ in the number of paired BES hits. Interestingly, when considering the total number of paired BES that map on the same chromosome, the percentage of paired BES mapping within $50-500 \mathrm{~kb}$ is $>40 \%$ in all plants except $A$. thaliana and $M$. truncatula. For example, $55 \%$ of all paired BES mapping on the same poplar chromosome do so within the prescribed distance. As poplar chromosomes are on average $20 \mathrm{Mb}$ in length, these data show that the mapping loci are not randomly distributed in the poplar genome, which supports our conclusion that our hits reflect true syntenic relationships.

Due to the high synteny degree detected between the melon and cucumber genomes, the latter was chosen for an additional synteny analysis performed using the recently published melon physical map of fingerprinted BACs from the BCM library [28]. The cucumber genome assembly together with all BCM BES were tested against the physical map using the draft sequence functions of the FPC software as described in the Methods section. All 320 physical contigs built from at least 15 BAC clones were analyzed and $37.5 \%$ were found to contain four of more BES mapping in a contiguous cucumber region greater than $40 \mathrm{~kb}$. A detailed list of the positive melon FCP contigs, cucumber contigs and lengths of the detected synteny regions can be found in the Additional File 1 Table S1. In addition, the SyMAP software package, whose role is to compute and display synteny blocks between physical maps and genome sequences from different species $[48,49]$, was used to obtain graphical representations of the collinear regions between melon and cucumber. Figure 1 shows an example of such a synteny region.

Previous results have shown that the network of microsynteny found between melon and the sequenced genomes of $A$. thaliana, poplar and $M$. truncatula results 
Table 6 Comparative mapping of C. melo BES to other plant genomes

\begin{tabular}{|c|c|c|c|c|c|c|c|c|c|c|c|}
\hline \multicolumn{3}{|c|}{ Plant genomes } & \multirow[t]{2}{*}{$\begin{array}{c}\text { No. of } \\
\text { masked } \\
\text { BES with } \\
\text { BLAST } \\
\text { matches }^{1}\end{array}$} & \multirow[t]{2}{*}{$\begin{array}{c}\text { No. of } \\
\text { masked } \\
\text { BES pairs } \\
\text { withM } \\
\text { BLAST } \\
\text { matches }^{2,3}\end{array}$} & \multicolumn{2}{|c|}{$\begin{array}{c}\text { On same } \\
\text { chromosome, } \\
\text { contig or } \\
\text { scaffold }^{3,4}\end{array}$} & \multicolumn{2}{|c|}{$\begin{array}{c}\text { Within } \\
50-500 \mathrm{~kb}^{3,4}\end{array}$} & \multirow[t]{2}{*}{$\begin{array}{c}\text { In the } \\
\text { correct } \\
\text { orientation }^{3,4}\end{array}$} & \multirow[t]{2}{*}{$\%^{5}$} & \multirow[t]{2}{*}{ Total $\%^{6}$} \\
\hline Species & $\begin{array}{l}\text { Pseudo_ } \\
\text { molecules }\end{array}$ & $\begin{array}{c}\text { Length } \\
(\mathrm{Mb})^{8}\end{array}$ & & & & $\begin{array}{c}\text { No. of } \\
\text { mapping } \\
\text { Loci }^{9}\end{array}$ & & $\begin{array}{c}\text { No. of } \\
\text { mapping } \\
\text { loci }\end{array}$ & & & \\
\hline A. thaliana & 5 & 135 & $2,958(6.3 \%)$ & $\begin{array}{c}135 \\
(0.4 \%)\end{array}$ & $\begin{array}{c}86 \\
(63.7 \%)\end{array}$ & $\begin{array}{l}111 \\
(1.3)\end{array}$ & 15 (17\%) & 15 & $\begin{array}{c}11 \\
(73 \%)\end{array}$ & 8 & 0.05 \\
\hline V. vinifera & 19 & 487 & 4,919 (10.4\%) & $\begin{array}{c}334 \\
(1.5 \%)\end{array}$ & $\begin{array}{c}195 \\
(58.4 \%)\end{array}$ & $\begin{array}{l}350 \\
(1.8)\end{array}$ & $86(44 \%)$ & 91 & $\begin{array}{c}56 \\
(65 \%)\end{array}$ & 17 & 0.26 \\
\hline G. $\max$ & 20 & 975 & 4,446 (9.4\%) & $\begin{array}{c}282 \\
(1.3 \%)\end{array}$ & $\begin{array}{c}171 \\
(60.6 \%)\end{array}$ & $\begin{array}{l}437 \\
(2.6)\end{array}$ & $73(43 \%)$ & 120 & $\begin{array}{c}57 \\
(78 \%)\end{array}$ & 20 & 0.26 \\
\hline M. truncatula & 8 & 241 & $3,214(6.8 \%)$ & $\begin{array}{l}155 \\
(0.7 \%)\end{array}$ & $\begin{array}{c}102 \\
(65.8)\end{array}$ & $\begin{array}{l}210 \\
(2.0)\end{array}$ & $30(29 \%)$ & 36 & $\begin{array}{c}24 \\
(80 \%)\end{array}$ & 15 & 0.11 \\
\hline P. trichocarpa & 19 & 370 & 4,676 (9.9\%) & $\begin{array}{c}315 \\
(1.4 \%)\end{array}$ & $\begin{array}{c}171 \\
(54.3 \%)\end{array}$ & $\begin{array}{l}276 \\
(1.6)\end{array}$ & $95(55 \%)$ & 123 & $\begin{array}{c}76 \\
(80 \%)\end{array}$ & 24 & 0.35 \\
\hline C. sativus $^{10}$ & 117 & 149 & $30,818(65.4 \%)$ & $10,296(47.6 \%)$ & $\begin{array}{c}6,475 \\
(62.9 \%)\end{array}$ & $\begin{array}{c}31,385 \\
(4.8)\end{array}$ & 4,945 (76\%) & 17,456 & $\begin{array}{l}4,138 \\
(84 \%)\end{array}$ & 40 & 19.14 \\
\hline
\end{tabular}

${ }^{1}$ Percentage relative to the total number of high-quality BES $(47,140)$

${ }^{2}$ Percentage relative to the total number of pairs of high-quality BES $(43,224 / 2)$

${ }^{3}$ Paired-BES mapping on several genome locations are counted once

${ }^{4}$ Percentage relative to the values in the previous column

${ }^{5}$ Percentage of paired BES with BLAST matches mapping on same chromosome/contig/scaffold within 50-500 kb in the correct orientation

${ }^{6}$ Percentage relative to the total number of paired-BES

${ }^{7}$ Number of pseudomolecules/scaffolds used for the analysis. In all cases except C. sativus, pseudomolecules correspond to chromosomes

${ }^{8}$ Total length of the genomic sequences used for the analysis

${ }^{9}$ In parenthesis, average number of mapping loci of pairs of BES mapping on same chromosome/contig/scaffold

${ }^{10}$ Scaffolds $>500 \mathrm{~kb}$, representing $73.4 \%$ of the $C$. sativus genome assembly deposited $\mathrm{n}$ the Phytozome v5 database.

from the polyploid structure of those genomes, which reflect ancient whole genome duplications [35]. We therefore determined the number of times each BES pair generated hits on the same chromosome (Table 6). In poplar, soybean, grapevine and $M$. truncatula, each BES pair fulfilling the first of the syntenic conditions listed above mapped twice, on average, onto the subject genome. This fell to 1.3 in A. thaliana but climbed to 4.8 in cucumber. These figures seem to indicate a genome duplication event in a common ancestor of melon and cucumber as well as another, more ancient event affecting a common ancestor of all the dicotyledonous species we analyzed. We also noted that $\sim 83 \%$ of BES pairs mapping to more than one locus mapped to different chromosomes, suggesting a major role of whole-genome/chromosomal duplications rather than intrachromosomal segmental duplications as an explanation for the large number of multiple mapping pairedBES.

The analysis of 348 melon genetic markers suggested that cucumber chromosomes 1, 2, 3, 4, 5 and 6 are collinear with melon chromosomes $2 / 12,3 / 5,4 / 6,9 / 10$, and $8 / 11$, respectively [47]. This suggests that each cucumber chromosome originated from the fusion of two ancestral chromosomes after cucurbit speciation. Several interchromosomal and intrachromosomal rearrangements have also been described [47]. Given the high number of paired melon BES showing collinearity with the cucumber genome, the data presented here will provide further insight into the dynamic evolution of these genomes, particularly once the current low contiguity of the cucumber genome sequence has been addressed.

\section{Conclusion}

We have sequenced BAC-ends from 33,024 clones, half from an existing BAC library produced using restriction endonucleases and the remainder from a newly constructed random shear BAC library. The resulting sequences confirmed that the random shear library is more representative of the melon genome than the restriction library, with less bias against repetitive DNA and fewer gaps. The sequences covered $\sim 4.2 \%$ of the melon genome, providing data on the abundance and distribution of microsatellites, TEs and coding DNA, and synteny between melon paired-BES and six other dicotyledonous plant genomes. In particular, we observed sequence conservation and synteny between the melon and cucumber genomes. These results showed that useful comparative genomic information can be derived using a large scale BAC-end sequencing 


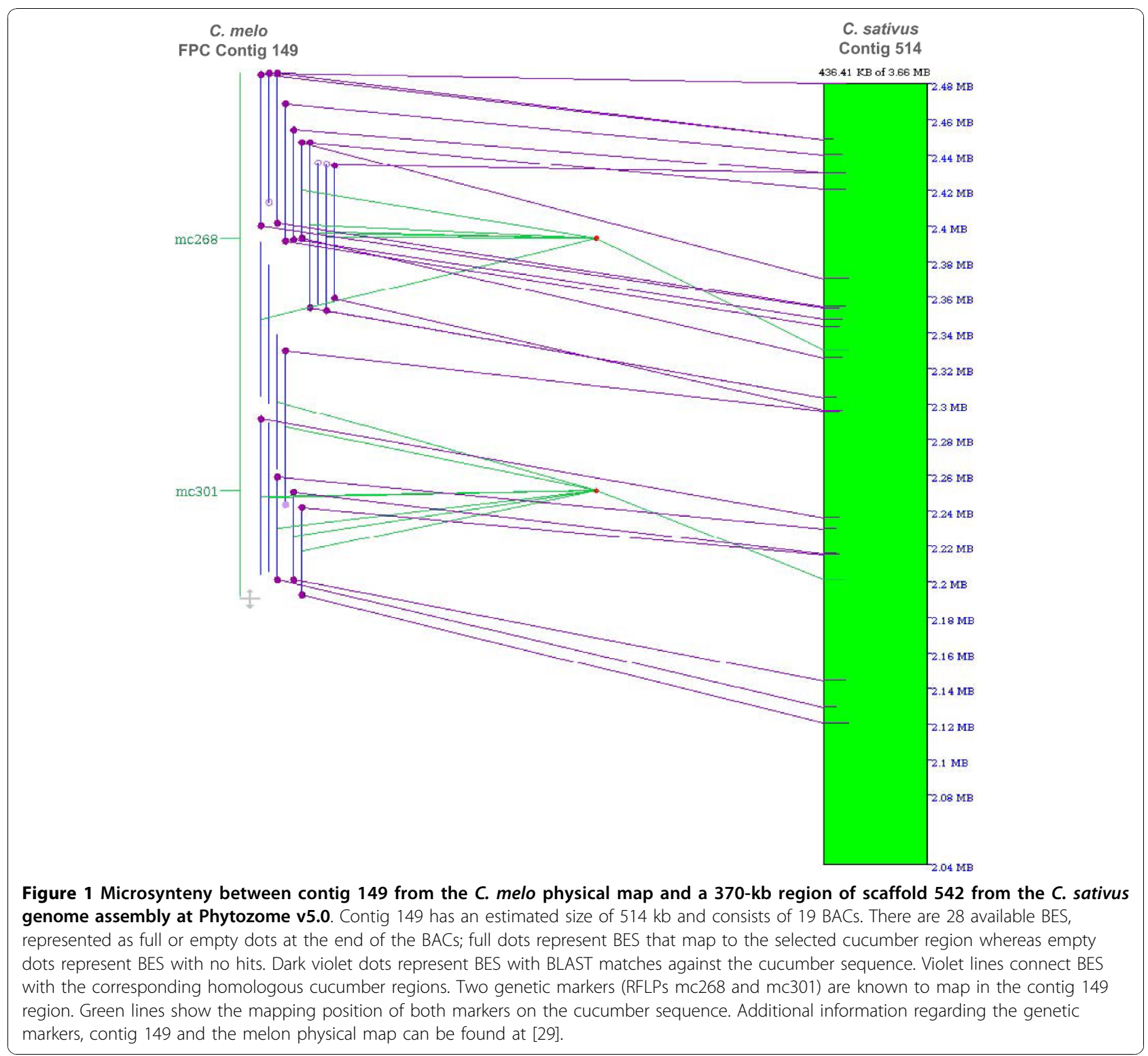

approach by anchoring a small proportion of the melon genome to other sequenced genomes.

\section{Methods}

Melon genotype and BAC library construction

Young leaves from the double-haploid C. melo subsp. melo line PIT92 were used for BAC library construction. The BamHI BAC library (BCM) was previously constructed in our laboratory [11]. It comprises 23,040 clones (average insert size $139 \mathrm{~kb}, 20 \%$ empty clones) distributed in 60 384-well plates, representing 5.7 genomic equivalents of the haploid melon genome.

A second BAC library (RCM) was constructed by Lucigen ${ }^{\circ}$ Co. (Middleton, Wisconsin) using randomly sheared melon genomic DNA. The resulting fragments were size selected and inserted into the transcriptionfree BAC vector (Lucigen ${ }^{\circ}$ ). It comprises 30,720 clones (average insert size $120 \mathrm{~kb}, 77 \%$ clones containing melon nuclear genomic DNA) distributed in 80 384-well plates, representing 6.4 genomic equivalents of the haploid melon genome.

\section{BAC-end sequencing}

BAC-end sequences representing 16,512 clones from the BCM library and 16,512 clones from the RCM library were generated by GATC Biotech (Constance, Germany). The software Phred was used for base calling and sequence trimming. Vector masking was achieved using the Sequencher 4.1.1 software package. BAC clones carrying Escherichia coli genomic inserts or 
melon organellar genomic DNA were removed using BLASTN similarity searches. BES shorter than $50 \mathrm{bp}$ were discarded.

\section{BAC-end clustering and assembly}

Cleaned, high-quality BES from the BCM and RCM libraries were clustered independently using the Sequencher 4.1.1 software package with a minimum overlap of 80 , and a minimum match of $95 \%$. The resulting assemblies from both sets of BES were jointly clustered to produce a final set of high-quality and nonredundant sequences. This yielded three sets of nonredundant sequences (referred to as 'BCM', 'RCM' and 'BCM-RCM' sequences) for subsequent analysis.

\section{Analysis of repetitive elements}

Non-redundant sequences were scanned for SSRs using msatcommander 0.8.2. SSRs considered for the final dataset included 1-3 nt repeats at least $12 \mathrm{nt}$ in length, and 4-6 nt repeats with at least four unit repetitions. TEs, telomere-related sequences and rRNAs were identified using RepeatMasker 3.2.8 (parameters: cross-match search engine, default speed/sensitivity and $A$. thaliana DNA source) and the plant repeat databases at http:// plantrepeats.plantbiology.msu.edu/ with a cut-off value of $1 \times 10^{-20}$. All identified repeat elements were masked to produce high-quality, non-redundant and masked melon genomic sequences.

\section{Identification of coding regions}

Non-redundant and masked BCM-RCM sequences were tested against the 23,762 sequences in the melon unigene database v3 [6] using E values of $1 \times 10^{-20}$ and $1 \times 10^{-50}$.

Sequences that did not match the melon database were tested against other cucurbit unigene databases (81,401 unigenes from the cucumber EST collection v2 and 4,719 unigenes from the watermelon EST collection v1) [6] using the same E values. Sequences with no matches in any curcubit EST databases were finally tested against all non-cucurbit plant EST assembly databases found at http://www.plantgdb.org.

\section{Comparative genome mapping}

All BES were mapped against the following genome sequences from the Phytozome v5.0 database http:// www.phytozome.net: A. thaliana (five chromosomes, TAIR release 9 ), $P$. trichocarpa (19 chromosomes, from JGI, v2), M. truncatula (8 chromosomes, Mt3.0 from the US/EU M. truncatula Genome Sequencing Project), G. $\max (20$ chromosomes, from the Soybean Genome Project, v1), V. vinifera (19 chromosomes, French-Italian Public Consortium for Grapevine Genome Characterization, September 2007 release) and C. sativus (117 scaffolds > $500 \mathrm{~kb}$, Roche 454-XLR assembly). The homology searches were performed using Discontiguous Megablast with an $\mathrm{E}$ value of $1 \times 10^{-20}$.

\section{Integration with the melon physical map and representation of synteny}

Cleaned, high-quality BES from the BCM library together with the cucumber genome sequence assembly were added to the current C. melo FPC physical map [28] using the draft sequence functions of the FPC V9.3 software package http://www.agcol.arizona.edu/software/fpc/ as follows: BSS function using MegaBLAST with E-value $1-20$, Identity $>80 \%$, Match $>80 \%$, followed by the Draft Sequence Integration function with parameters: Window size, $200 \mathrm{~kb}$, Min Bes Hit, 4, and Top N, 0. Also, the complete set of BCM BES, the physical map information and the sequences of genetic markers anchored to the map were loaded into the SyMAP v3.1 software package http://www.agcol.arizona.edu/software/symap/ to display areas of synteny between the melon physical map and the sequenced chromosomes of C. sativus.

\section{Additional material}

Additional file 1: Table S1. Mapping of C. melo BES to the C. sativus genome using the melon FPC physical map.

\section{Acknowledgements}

We gratefully acknowledge Núria Aventín (CRAG, Barcelona, Spain) for technical assistance in the culture and replica plating of BAC clones. This project was carried out in the frame of the MELONOMICS project (20092012) of the Fundación Genoma España, and also supported by funding of the Consolider-Ingenio 2010 Programme of the Spanish Ministerio de Ciencia e Innovación (CSD2007-00036 "Center for Research in Agrigenomics").

Note: The Cucumis melo BAC-end sequences are available in the DDBJ/ EMBL/GenBank databases under the accession numbers HN291986HN339125 as well as in the Spanish melon genome sequencing project webpage http://melonomics.upv.es/public_files.

\section{Author details}

${ }^{1}$ Molecular Genetics Department, Center for Research in Agricultural Genomics CRAG (CSIC-IRTA-UAB), Jordi Girona, 18-26, 08034 Barcelona, Spain. ${ }^{2}$ Departamento de Biología del Estrés y Patología Vegetal, Centro de Edafología y Biología Aplicada del Segura (CEBAS) - CSIC, Apdo. correos 164, 30100 Espinardo (Murcia), Spain. ${ }^{3}$ IRTA, Center for Research in Agricultural Genomics CRAG (CSIC-IRTA-UAB), Carretera de Cabrils Km 2, 08348 (Barcelona), Spain.

\section{Authors' contributions}

VMG and LRM carried out the trimming, clustering and analysis of the BACend sequences of both BAC libraries and elaborated this manuscript. EC and $A B$ provided bioinformatic analysis support; $E C$ also contributed to the synteny analysis. MAA generated and sent to LUCIGEN ${ }^{\circledast}$ plant melon material for the construction of the second BAC library. PP is the main coordinator of the MELONOMICS project and participated in the conception of the study together with JGM and MAA. MAA is the principal investigator and supervised the writing of the manuscript. All authors read and approved the final manuscript.

Received: 13 July 2010 Accepted: 5 November 2010

Published: 5 November 2010 


\section{References}

1. The food and agriculture organization of the United Nations. [http:// www.fao.org/]

2. Arumuganathan $\mathrm{K}$, Earle ED: Nuclear DNA content of some important plant species. Plant Mol Biol Rep 1991, 9:208-218.

3. Çürük $S$, Centiner S, Elman C, Xia X, Wang Y, Yeheskel A, Zilberstein L, PerlTreves R, Watad A, Gaba V: Transformation of recalcitrant melon (Cucumis melo L.) cultivars is facilitated by wounding with carborundum. Eng Life Sci 2005, 5:169-177.

4. Nuñez-Palenius HG, Gómez-Lim M, Ochoa-Alejo N, Grumet R, Lester G, Cantliffe DJ: Melon fruits: genetic diversity, physiology, and biotechnology features. Crit Rev Biotechnol 2008, 28:13-55.

5. Ayub R, Guis M, Amor MB, Gillot L, Roustan J-P, Latché A, Bouzayen M, Pech JC: Expression of ACC oxidase antisense gene inhibits ripening of cantaloupe melon fruits. Nat Biotechnol 1996, 14:862-866.

6. The International Cucurbit Genomics Initiative (ICuGI). [http://www.icugi. org].

7. Deleu W, Esteras C, Roig C, González-To M, Fernández-Silva I, GonzálezIbeas D, Blanca J, Aranda MA, Arús P, Nuez F, Monforte AJ, Picó MB, GarciaMas J: A set of EST-SNPs for map saturation and cultivar identification in melon. BMC Plant Biology 2009, 9:90.

8. The National Center for Biotechnology Information. [http://www.ncbi.n/m. nih.gov].

9. Ezura H, Fukino N: Research tools for functional genomics in melon (Cucumis melo L.): Current status and prospects. Plant Biotechnololy 2009, 26:359-368.

10. Luo $M$, Wang $Y H$, Joobeur $T$, Wing RA, Dean RA: Melon bacterial artificial chromosome (BAC) library construction using improved methods and identification of clones linked to the locus conferring resistance to melon Fusarium wilt (Fom-2). Genome 2001, 44:154-162.

11. van Leeuwen $H$, Monfort $A$, Zhang $H B$, Puigdomènech $P$ : Identification and characterisation of a melon genomic region containing a resistance gene cluster from a constructed BAC library. Microcolinearity between Cucumis melo and Arabidopsis thaliana. Plant Mol Biol 2003, 51:703-718.

12. Mascarell-Creus A, Cañizares J, Vilarrasa-Blasi J, Mora-García S, Blanca J, Gonzalez-lbeas D, Saladié M, Roig C, Deleu W, Picó-Silvent B, López-Bigas N, Aranda MA, Garcia-Mas J, Nuez F, Puigdomènech P, Caño-Delgado Al: An oligo-based microarray offers novel transcriptomic approaches for the analysis of pathogen resistance and fruit quality traits in melon (Cucumis melo L.). BMC Genomics 2009, 10:467

13. Ophir R, Eshed R, Harel-Beja R, Tzuri G, Portnoy V, Burger Y, Uliel S, Katzir N, Sherman A: High-throughput marker discovery in melon using a selfdesigned oligo microarray. BMC Genomics 2010, 11:269.

14. Tadmor Y, Katzir N, Meir A, Yaniv-Yaakov A, Sa'ar U, Baumkoler F, Lavee T, Lewinsohn E, Schaffer A, Buerger J: Induced mutagenesis to augment the natural genetic variability of melon (Cucumis melo L.). Israel J Plant Sci 2007, 55:159-169.

15. Nieto C, Piron F, Dalmais M, Marco CF, Moriones E, Gómez-Guillamón ML, Truniger V, Gómez P, Garcia-Mas J, Aranda MA, Bendahmane A: EcoTILLING for the identification of alleclic variants of melon elF4E, a factor that controls virus susceptibility. BMC Plant Biol 2007, 7:34.

16. Eduardo I, Arús P, Monforte AJ: Development of a genomic library of nea isogenic lines (NILs) in melon (Cucumis meloL.) from the exotic accession PI161375. Theor Appl Genet 2005, 112:139-148.

17. Han Y, Chagné D, Gasic K, Rikkerink EHA, Beever JE, Gardiner SE, Korbana SS: BAC-end sequence-based SNPs and Bin mapping for rapid integration of physical and genetic maps in apple. Genomics 2009, 93:282-8.

18. Warren RL, Varabei D, Platt D, Huang X, Messina D, Yang S-P, Kronstad JW, Krzywinski M, Warren WC, Wallis JW, Hillier LW, Chinwalla AT, Schein JE, Siddiqui AS, Marra MA, Wilson RK, Jones SJM: Physical map-assisted whole-genome shotgun sequence assemblies. Genome Res 2006, 16:768-775.

19. Wang $\mathrm{YH}$, Thomas CE, Dean RA: A genetic map of melon (Cucumis melo L.) based on amplified fragment length polymorphism (AFLP) markers. Theor Appl Genet 1997, 95:791-798.

20. Danin-Poleg Y, Reis N, Baudracco-Arnas S, Pitrat M, Staub JE, Oliver M Arus $P$, deVicente $C M$, Katzir N: Simple sequence repeats in Cucumis mapping and map merging. Genome 2000, 43(6):963-974.

21. Perin C, Hagen S, De Conto V, Katzir N, Danin-Poleg Y, Portnoy V, Baudracco-Arnas S, Chadoeuf J, Dogimont C, Pitrat M: A reference map of
Cucumis melo based on two recombinant inbred line populations. Theor Appl Genet 2002, 104(6-7):1017-1034.

22. Silberstein L, Kovalski I, Brotman Y, Perin C, Dogimont C, Pitrat M, Klingler J, Thompson G, Portnoy V, Katzir N, Perl-Treves R: Linkage map of Cucumis melo including phenotypic traits and sequence-characterized genes. Genome 2003, 46:761-773.

23. Fernandez-Silva I, Eduardo I, Blanca J, Esteras C, Pico B, Nuez F, Arus P, Garcia-Mas J, Monforte AJ: Bin mapping of genomic and EST-derived SSRs in melon (Cucumis melo L.). Theor Appl Genet 2008, 118(1):139-150.

24. Deleu W, Esteras C, Roig C, González-To M, Fernández-Silva I, GonzálezIbeas D, Blanca J, Aranda MA, Arús P, Nuez F, Monforte AJ, Picó MB, GarciaMas J: A set of EST-SNPs for map saturation and cultivar identification in melon. BMC Plant Biology 2009, 9:90.

25. Cuevas HE, Staub JE, Simon PW, Zalapa JE: A consensus linkage map identifies genomic regions controlling fruit maturity and beta-caroteneassociated flesh color in melon (Cucumis melo L.). Theor Appl Genet 2009, 119:741-56.

26. Monforte AJ, Oliver M, Gonzalo MJ, Alvarez JM, Dolcet-Sanjuan R, Arus P: Identification of quantitative trait loci involved in fruit quality traits in melon (Cucumis melo L.). Theor Appl Genet 2004, 108:750-758.

27. Harel-Beja R, Tzuri G, Portnoy V, Lotan-Pompan M, Lev S, Cohen S, Dai N, Yeselson L, Meir A, Libhaber SE, Avisar E, Melame T, van Koert P, Verbakel H, Hofstede R, Volpin H, Oliver M, Fougedoire A, Stalh C, Fauve J, Copes B, Fei Z, Giovannoni J, Ori N, Lewinsohn E, Sherman A, Burger J, Tadmor Y, Schaffer AA, Katzir N: A genetic map of melon highly enriched with fruit quality QTLs and EST markers, including sugar and carotenoid metabolism genes. Theor Appl Genet 2010, (Epub).

28. González V, Garcia-Mas J, Arús P, Puigdomènech P: Generation of a BACbased physical map of the melon genome. BMC Genomics 2010, 11:339.

29. Cheung F, Town CD: A BAC end view of the Musa acuminata genome. BMC Plant Biology 2007, 7:29

30. Febrer M, Cheung F, Town CD, Cannon SB, Young ND, Abberton MT, Jenkins G, Milbourne D: Construction, characterization, and preliminary BAC-end sequencing analysis of a bacterial artificial chromosome library of white clover (Trifolium repens L.). Genome 2007, 50:412-21.

31. Han Y, Korban SS: An overview of the apple genome through BAC end sequence analysis. Plant Mol Biol 2008, 67:581-588.

32. Osoegawa K, Vessere GM, Shu CL, Hoskins RA, Abad JP, de Pablos B, Villasante $A$, de Jong PJ: BAC clones generated from sheared DNA. Genomics 2007, 89:291-299.

33. Yu C, Li Z: Construction of methylation-sensitive partial restriction bacterial artificial chromosome libraries in maize. Anal Biochem 2006, 359:141-143.

34. Ammiraju JS, Yu Y, Luo M, Kudrna D, Kim H, Goicoechea JL, Katayose $Y$, Matsumoto T, Wu J, Sasaki T, Wing RA: Random sheared fosmid library as a new genomic tool to accelerate complete finishing of rice (Oryza sativa spp. Nipponbare) genome sequence: sequencing of gap-specific fosmid clones uncovers new euchromatic portions of the genome. Theor Appl Genet 2005, 111:1596-607.

35. Deleu W, González V, Monfort A, Puigdomènech P, Arús P, Garcia-Mas J: Structure of two melon regions reveals high microsynteny with sequenced plant species. Mol Genet Genomics 2007, 278:611-622.

36. van Leeuwen $H$, Garcia-Mas J, Coca $M$, Puigdomènech $P$, Monfort A Analysis of the melon genome in regions encompassing TIR-NBS-LRR resistance genes. Mol Gen Genomics 2005, 273:240-251.

37. Datema E, Mueller LA, buels R, Giovannoni JJ, Visser RGF, Stiekema WJ, van Ham RCHJ: Comparative BAC end sequence analysis of tomato and potato reveals overrepresentation of specific gene families in potato. BMC Plant Biology 2008, 8:34

38. Terol J, Naranjo MA, Ollitrault P, Talon M: DEvelopment of genomic resources for Citrus clementina: Characterization of three deep-coverage BAC libraries and analysis of $46,000 \mathrm{BAC}$ end sequences. BMC Genomics 2008, 9:423.

39. Lai CW JL, Yu Q, Hou S, Skelton RL, Jones MR, Lewis KLT, Murray J, Eustice M, guan P, Agbayani R, Moore PH, Ming R, Presting GG: Analysis of papaya $B A C$ end sequences reveals first insights into the organization of a fruit tree genome. Mol Gen Genomics 2006, 276:1-12.

40. Cardle L, Ramsay L, Milbourne D, Macaulay M, Marshall D, Waugh R: Computational and experimental characterization of physically clustered simple sequence repeats in plants. Genetics 2000, 156:847-854. 
41. Varshney RK, Graner A, Sorrells ME: Genic microsatellite markers in plants: features and applications. Trends in Biotechnology 2005, 23:48-55.

42. Jo SH, Koo DH, Kim JF, Hur CG, Lee S, Yang TJ, Kwon SY, Choi D: Evolution of ribosomal DNA-derived satellite repeat in tomato genome. BMC Plant Biology 2009, 9:42.

43. Mudge J, Cannon SB, Kalo P, Oldroyd GE, Roe BA, Town CD, Young ND: Highly syntenic regions in the genomes of soybean, Medicago truncatula, and Arabidopsis thaliana. BMC Plant Biology 2005, 5:15.

44. Tang H, Bowers JE, Wang X, Ming R, Alam Maqsudul, Paterson AH: Synteny and collinearity in Plant genomes. Science 2008, 320(5875):486-488.

45. Ramakrishna W, Bennetzen JL: Genomic colinearity as a tool for plant gene isolation. Methods Mol Biol 2003, 236:109-122.

46. Nieto C, Morales M, Orjeda G, Clepet C, Monfort A, Sturbois B, Puigdomenech P, Pitrat M, Caboche M, Dogimont C, Garcia-Mas J, Aranda M, Bendahmane A: An elF4E allele confers resistance to an uncapped and non-polyadenylated RNA virus in melon. Plant J 2006, 48:452-462.

47. Huang S, Li R, Zhang Z. Li L, Gu X, Fan W, Lucas W J, Wang X, Xie B, Ni P, et al: The genome of the cucumber, Cucumis sativus L. Nature genetics 2009, 41:1275-1281.

48. Nelson W, Soderlund C: Integrating sequence with FPC fingerprint maps. Nucleic Acids Research 2009, 37:e36.

49. Soderlund C, Nelson W, Shoemaker A, Paterson A: SyMAP: A system for discovering and viewing syntenic regions of FPC maps. Genome Research 2006, 16:1159-1168.

doi:10.1186/1471-2164-11-618

Cite this article as: González et al:: Genome-wide BAC-end sequencing of Cucumis melo using two BAC libraries. BMC Genomics 2010 11:618.

\section{Submit your next manuscript to BioMed Central and take full advantage of:}

- Convenient online submission

- Thorough peer review

- No space constraints or color figure charges

- Immediate publication on acceptance

- Inclusion in PubMed, CAS, Scopus and Google Scholar

- Research which is freely available for redistribution

Submit your manuscript at www.biomedcentral.com/submit 